\title{
Quantas vidas tem Gisberta?: imagem, mídia e arquivo na narrativa contemporânea
}

\author{
MANAÍRA AIRES ATHAYDE
}

Stanford University

\begin{abstract}
In early 2006, fourteen Portuguese teenagers murdered Gisberta Salce, a Brazilian transgender woman, in Porto. A long and emotional criminal trial followed. Since then, several literary and artistic works inspired by Gisberta's life and tragic death have emerged in both Portugal and Brazil. In the present article, I argue first that these works are intertextually related; I then show how they are connected through a contemporary artistic, social, and political ecology. At the center of this ecology-besides the image of Gisberta herself-is the complex relation between art, technology, and media in a digital world marked by a rapid transnational flow of information and new modes of archival design.
\end{abstract}

Keywords: Digital humanities, gender, Brazil, Portugal, archive

Era uma manhã fria de fevereiro na cidade do Porto, no norte de Portugal. Não é difícil imaginar o cheiro úmido que sai daqueles edifícios seculares do centro da cidade, com as suas enviesadas ruelas e becos. Ali, viveu Gisberta. Ali, morreu Gisberta. Gisberta Salce Júnior, ou a "Gis,” como era conhecida, nasceu em São Paulo e, nos anos 1990, com 19 anos, decidiu emigrar para Portugal. Disse à família que iria embora para fugir da violência contra as transexuais: uma amiga sua havia sido brutalmente assassinada meses antes. Depois de uma temporada na França, escolheu o Porto como refúgio, onde viveu por mais de duas décadas e ficou conhecida como a diva brasileira da noite portuense, fazendo espetáculos de transformismo em conhecidas casas noturnas da época. Naquela cidade, na manhã de 22 de fevereiro de 2006, Gisberta é encontrada morta num edifício em construção abandonado. O crime ganha enorme repercussão midiática. 14 jovens, 
entre os 12 e os 16 anos, participaram do espancamento de Gisberta durante quase uma semana e, depois, jogaram-na ainda viva no poço daquela construção embargada. Gisberta, que era toxicodependente e havia contraído o vírus HIV, já vivia há algum tempo ali, numa barraca improvisada, e estava com a saúde bastante comprometida. O caso se torna ainda mais midiático quando o julgamento dos jovens traz uma reviravolta: vem a público que a maior parte deles era vítima de algum tipo de abuso (físico, sexual, psicológico) cometido na instituição católica que os acolhia, mantida pelo Estado português para salvaguardar jovens em situação de risco. O processo, então, acabou por se arrastar ao longo daquele ano, num caso duríssimo marcado pela violência nas suas mais diversas faces.

Mais de dez anos se passaram. Durante esse tempo, foram surgindo, em Portugal e no Brasil, várias obras literárias e artísticas em torno do caso. Poucos meses depois da tragédia, ainda no ávido calor dos acontecimentos, o documentário Gisberta-Liberdade é realizado por Jó Bernardo e Jo Schedlbauer, ativistas da European Transgender Network. No ano seguinte, o cantautor português Pedro Abrunhosa lança a canção "Balada de Gisberta,” que compôs para o álbum Luz. Também em 2007 é publicado o poema-livro Indulgência plenária, do escritor português Alberto Pimenta. Meninos de ninguém-o caso Gisberta e outras histórias, da jornalista Ana Cristina Pereira, chega às livrarias portuguesas em 2009. Já no Brasil, um ano depois, vem a lume o romance Do fundo do poço se vê a lua, de Joca Reiners Terron, que recebeu o Prêmio Machado de Assis 2010, da Biblioteca Nacional Brasileira. Naquele mesmo ano de 2010, a música de Abrunhosa é interpretada por Maria Bethânia no DVD Amor festa devoção, encerrando o primeiro ato do espetáculo. E é esta versão da música que leva o cineasta brasileiro Thiago Carvalhaes, que estava em Portugal participando de uma residência artística, a ter contato pela primeira vez com a história de Gisberta, acabando por realizar o premiado curta-metragem A Gis, filmado numa co-produção luso-brasileira e então lançado quando o assassinato completava uma década. O filme ganhou mais de uma dezena de prêmios, incluindo o de melhor curta-metragem no Grande Prêmio do Cinema Brasileiro 2017 e no $45^{\circ}$ Festival de Gramado. Além disso, foi naquele mesmo ano de 2016 que o ator brasileiro Luis Lobianco, ao ouvir a canção na voz de Bethânia, se interessou em saber mais sobre aquela balada tão triste. Conseguiu, no ano seguinte, levar aos palcos a peça teatral Gisberta, com texto de Rafael Souza- 
Ribeiro e direção de Renato Carrera. Em 2013, no entanto, já havia sido realizada outra peça também intitulada Gisberta, um monólogo escrito pelo encenador e ator luso-brasileiro Eduardo Gaspar e interpretado pela atriz portuguesa Rita Ribeiro. A peça recebeu o Prémio Arco-Íris 2014, outorgado pela Associação ILGA Portugal. Outro espetáculo teatral ainda entrou em cartaz, desta vez com o nome Balada de Gisberta, escrito e dirigido pelo dramaturgo brasileiro Renato Andrade, por ocasião dos dez anos da morte de Gisberta. E, no final de 2018, em Portugal, Afonso Reis Cabral publica o romance Pão de Açúcar, que ganhou o Prémio Saramago 2019.

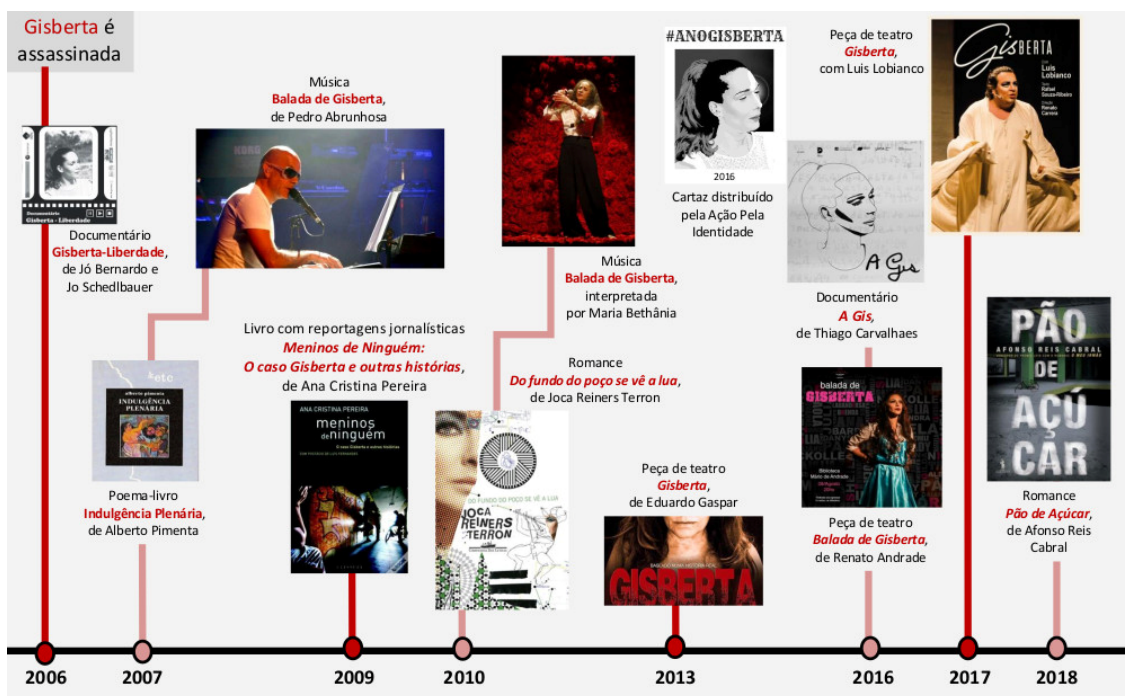

Fig. 1. Ao longo de mais de dez anos, foram surgindo diversas obras no cenário literário e artístico luso-brasileiro em torno de Gisberta.

Como se pode ver, é bastante substancial a lista de obras que foram aparecendo em meios diversos, sobretudo na segunda metade desta nossa década que chega agora ao fim. E mais substancial ainda é perceber como essas obras se interrelacionam, quer por algumas surgirem manifestadamente de outras, quer por fazerem citações intertextuais diretas ou, em suma, por estarem conectadas entre si através de uma ecologia experimentada neste início de século, em que o fluxo digital cria novos ritmos de produção, apropriação, interconexão e difusão de informações. Também é interessante observar que há aqui o sinal de 
Athayde

revigoramento de um espaço luso-brasileiro de criação, que parece vir, sobretudo a partir de projetos colaborativos e de trocas culturais facilitadas pelos recentes fluxos migratórios, amortecendo aquele "sismo cultural" que prevaleceu no século XX.

Assim, ao me deparar com esse cenário literário e artístico em que Gisberta renasce tantas e tantas vezes, foram surgindo várias inquietações que me levaram a questionar o que a multiplicidade ficcional de Gisberta pode nos dizer sobre a nossa iminente narrativa contemporânea e as imbricadas relações entre artes, tecnologias e mídias, num mundo marcado por céleres fluxos transnacionais de imagens. Da música à literatura, do teatro ao cinema, quais são as "zonas de contato” na ficcionalização de Gisberta e os seus estratagemas estéticos para lidar com os escombros do real? Ou melhor dizendo, será que se observarmos música, poema, romances, filme e peças de teatro encontraremos alguns traços em comum na ficcionalização de Gisberta? E de que maneira as reconfigurações de uma realidade hiperexposta tornam presente a atmosfera deste fim de década, início de século? Considerando que há uma série de trabalhos desenvolvidos nos últimos anos que se dedicam ao caso de Gisberta ou a obras que daí resultaram, interessa-me neste momento dar um outro passo, que consiste justamente em analisar aquelas obras em seu conjunto e as contribuições desse conjunto para se pensar os modos de circulação da imagem (e suas consequentes narrativas) nestes tempos high tech. Com efeito, o que desde o início podemos dizer é que, quando estamos diante desse amplo conjunto de obras, que mais parece funcionar como um movimento epifânico que nos conduz ao arrepio sintomático dos nossos dias, o prenúncio para as respostas vem do próprio silêncio a que Gisberta foi brutalmente submetida: na ausência dela, o que nos resta é o arquivo.

\section{Algumas medidas onde Gisberta, ausente, não cabe}

Comecemos por fazer uma espécie de patchwork com as obras mencionadas. Desde o início, é possível observar que o exercício de escuta ganha proporções importantes aqui, manifestando-se-quer enquanto caminho metodológico no processo de criação, quer como efeito que se espera provocar no público—nos diversos trabalhos literários e artísticos concebidos em torno de Gisberta, o que se torna ainda mais relevante por se tratar de uma pessoa que nunca pôde ser ouvida. Acontece que, em vez de se encenar a recriação de quem teve a voz 
silenciada, é justamente a ausência do seu testemunho que é amplificada e se torna o eixo transversal àquele conjunto de obras, o traço que sintomaticamente permanece nele. Se retratar personagens reais tende a evocar a escuta como "uma tentativa de compreender alguém que existiu," como nos lembra Renato Andrade (Alves Jr.), ao falar da sua peça Balada de Gisberta (2016), diríamos que a questão da escuta é levada ainda mais longe quando pensamos naquelas obras enquanto conjunto, uma vez que a música "Balada de Gisberta” (2007), de Pedro Abrunhosa, teve um papel decisivo no surgimento de muitas outras obras, como daqui a pouco veremos.

Antes, sublinhe-se o aspecto relevante que é a canção ter sido composta na primeira pessoa, recriando a voz de Gisberta, enquanto quase todas as demais obras procuraram não encarnar a personagem, acabando por adotar discursos em terceira pessoa ou assumindo "olhares de fora sobre Gisberta," como afirma Luis Lobianco (Horta), idealizador da peça Gisberta (2017). Ele vai dizer: "Estamos falando da verdade de uma pessoa que foi subitamente tirada de todas as suas possiblidades de falar, de se defender. Foi brutalmente assassinada e a verdade dela foi com ela. Essa voz foi silenciada e ninguém pode falar por ela” (Beltrão). Lobianco, assim, resume uma perspectiva que, se já estava latente, tornou-se definitivamente manifesta nas obras que surgiram a partir do \#anogisberta, como ficou conhecida uma série de iniciativas, muitas das quais articuladas nas redes sociais, realizadas por ocasião dos dez anos do assassinato, em 2016. Nessa altura, também surgiram textos em blogues e reportagens publicadas em periódicos eletrônicos que ganharam imensa repercussão no Facebook e no Instagram, contribuindo para chamar a atenção daqueles autores para o caso.

A Gisberta-em-primeira-pessoa da canção "Balada de Gisberta” acabou, então, por representar o primeiro momento em que o violento caso é retratado por uma obra. Para além do paradigma de representação, Abrunhosa criou uma poderosa atmosfera (Gumbrecht) que fez com que a canção se tornasse, quase dez anos depois, um forte elo entre as obras que vieram surgir a partir do \#anogisberta. Como ainda recorda Luis Lobianco: "Naquele momento, pude ouvir pela primeira vez com atenção o tema cantado por Maria Bethânia e fiquei profundamente emocionado. Não conhecia a história de Gisberta, nunca tinha ouvido falar dela” (Horta), afirma com o espanto de quem não acredita que foram necessários dez anos para tanto, inclusive para que a história ganhasse maior repercussão no Brasil. O mesmo aconteceu com Thiago Carvalhaes, diretor do 
Athayde

filme A Gis (2016), que estava em Portugal quando escutou pela primeira vez a música cantada por Maria Bethânia. ${ }^{1}$ "Quando a ouvi,” Carvalhaes afirma, “eu me envolvi muito emocionalmente, foi uma coisa que fez o maior sentido para mim, e depois eu quis saber um pouco mais sobre a história da música. Mas estava tão difícil encontrar mais informações sobre Gisberta, porque as reportagens só falavam sobre os meninos que a tinham assassinado" (“Entrevista”).

Talvez esteja aí, nesse querer saber mais sobre Gisberta, em detrimento do midiático caso Gisberta, a diferença na maneira de vê-la na altura em que o crime aconteceu e de vê-la a partir das transformações que foram ocorrendo nesta nossa década, marcada pela larga projeção das questões de identidade num mundo cada vez mais online. Poderíamos mesmo dizer que "Balada de Gisberta” cantada por Pedro Abrunhosa, com a sua voz enrouquecida, numa versão intimista em que se sobressai o piano e na qual a letra é quase recitada, evoca uma espécie de luto, naqueles meados dos anos 2000. Já "Balada de Gisberta” cantada por Maria Bethânia, com a sua voz afetuosamente firme, numa versão marcada sobretudo pelo acompanhamento do violão, é um presságio desse "luto" que foi se tornando "luta” (aliás, palavras frequentes nas redes sociais e nestas frequentemente associadas) ao longo dos anos 2010. "E a dor é tão perto" é o verso final que Bethânia não canta: tenha sido intencional ou não, certo é que a sua versão da música acaba com a repetição insistente do verso “E o amor é tão longe.” Em primeira ou terceira pessoa, Gisberta está sempre ausente, distante, para que o seu nome possa ecoar.

A questão do nome se torna vital na maior parte daquelas obras, como inclusive prenuncia o primeiro verso daquela canção: “Perdi-me do nome.” No filme A Gis, esta problemática é o cerne do argumento: mostrando um apanhado de reportagens publicadas na altura, revela que os órgãos de comunicação, não sabendo como nomear Gisberta, optaram por tratá-la sempre no masculino ("o sem abrigo," “o travesti,” "indivíduo do sexo masculino,” “o Gisberto,” “o tixocodependente,” “o transexual”). Através de cartas e cartões-postais, o curtametragem se preocupa ainda em entender em que momento Gisberta começa a se reconhecer no feminino, mostrando que, a partir da sua ida para a Europa, no início dos anos 1980, passa a assinar “Gisbert S J.” A própria escolha do título

\footnotetext{
${ }^{1}$ Agradeço ao diretor Thiago Carvalhaes por me disponibilizar o filme A Gis.
} 
do filme realça o artigo feminino, fazendo referência à forma como Dona Angelina chama a filha numa carta que envia à família em 1993, quando vai visitar Gisberta no Porto—o logótipo do filme é a expressão “A Gis” decalcada da carta.

A ideia de que "esse documentário constrói um retrato delicado, peça por peça, de uma mulher despedaçada por um mundo indiferente," como lemos em sua sinopse, é o mesmo mecanismo de ficcionalização de Gisberta que vamos encontrar nas três peças de teatro que se enveredaram pelo universo dela. No filme, essa noção de que a personagem vai sendo construída a partir de testemunhos que se encaixam "peça por peça” no sempre incompleto quebracabeça da memória é trabalhada a partir da opção estética de se mostrar, primeiramente, o depoimento do entrevistado, que só ao fim é identificado, quando olha frontalmente para a câmera e surge uma legenda com o seu nome e profissão. No teatro, esse “encarar de frente,” com toda a necessidade enfática da redundância, é o que constrói a Gisberta que Luis Lobianco não interpreta: Lobianco encarna vários personagens, de familiares a amigos que conviveram com Gisberta, e "sem trocas de figurino, mudanças de cenário ou um ator vestido de mulher, o espectador é levado a imaginar e acaba por vislumbrar a figura de Gisberta, que vai sendo construída justamente pela sua ausência” (Costa e Gonçalves). Assim como se passa com a peça de Eduardo Gaspar, que é um monólogo da mãe de Gisberta e as suas dificuldades em "aceitar o seu menino": numa longa travessia repleta de culpas, vamos assistindo a uma mãe que “aprendeu a dizer o nome da filha, enquanto nós, espectadores, também vamos aprendendo a dizer o seu nome” (“Atribuição”), nas palavras que descreveram o espetáculo na cerimônia de entrega do Prémio Arco-Íris 2014, atribuído pela Associação ILGA Portugal.

Essa questão do nome já está presente, entretanto, numa obra muito anterior, no poema-livro Indulgência plenária (2007), de Alberto Pimenta. É notável ali a expectativa que vai sendo criada a respeito da personagem descrita desde o início, mas que somente é identificada em meados da segunda parte do poema (num livro composto por cinco partes), quando pela primeira vez o poeta diz: "A tua vida / foi o teu pecado / Gisberta” (24). O poema é composto por versos curtos, muitas vezes "interrompidos,” o que torna a leitura dura, incômoda, provocadora. Utiliza-se exaustivamente o artifício poético do transporte, em que se "quebra" um verso prolongando o seu sentido no(s) verso(s) subsequente(s), influindo 
decisivamente no ritmo e no significado com a introdução da pausa na leitura e a suspensão de sentido que se verifica na passagem de um verso para o seguinte. Esse recurso, considerado um dos mais importantes da poesia, revela como a palavra poética é a violência da linguagem, “torcendo” o significado das palavras cotidianas ao atribuir-lhes novos sentidos. É por isso que podemos dizer que a violência de um caso como o de Gisberta também está aqui formalmente contida no desalinhamento métrico e no encadeamento sintático entre um verso e outro, criando um ritmo de inquietação, de procura ou mesmo de confronto. Interessante observar que muitas vezes o poeta inicia uma palavra, a meio de um verso, com letra maiúscula, conseguindo chamar a atenção tanto para o significado dessa palavra no contexto estabelecido como criando um efeito de recomeço constante, de algo que acaba e não (re)começa no lugar esperado, dando forma à tensão instaurada a partir de uma coisa ruidosa, que vai emperrando, que vai se tornando sôfrega. De algo que tem início, mas não tem fim.

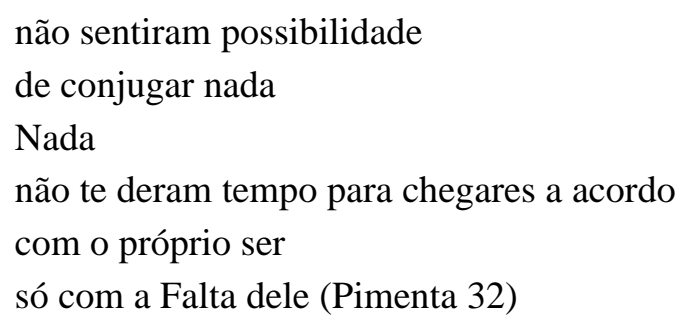

Essa "Falta” também persiste nas peças de teatro. São interpretados vários personagens que conviveram com Gisberta, de familiares a amigos, mas Gisberta, lá está, é sempre lembrada pela ausência. Gisberta é sempre a memória do outro. Rafael Souza-Ribeiro, que assina o texto do espetáculo realizado por Lobianco, ${ }^{2}$ afirma que, ao longo do processo de recolha de histórias, deparou-se com “discursos que não batiam certo. Como sabemos, a memória é uma invenção. Por isso, na peça, recordamos Gisberta mais pela ausência. Todas as personagens têm saudades da Gisberta” (“Foi a primeira vez”).

Diríamos, inclusive, que essa recordação pela ausência já se observa, embora de outra maneira, em Meninos de ninguém-o caso Gisberta e outras histórias

\footnotetext{
${ }^{2}$ Agradeço à produção do espetáculo Gisberta por ter me disponibilizado o texto Gisberta (dossiê pré-dramaturgia), escrito por Rafael Souza-Ribeiro.
} 
(2009). Nesse livro-reportagem, Gisberta está novamente presente-ausente, dado que o propósito da jornalista Ana Cristina Pereira é acompanhar, além de outros casos nas mesmas esferas, as histórias dramáticas de vida de alguns dos adolescentes envolvidos no crime. Como escreve Luís Fernandes, no posfácio:

As histórias de Meninos de ninguém põem-nos a pensar o que fez os sérgios e os celsos, as ritas e as marias que nelas falam, ser como são. Como foram dar naquilo? E, noutros casos, como se furtaram a ter de ser aquilo? E que sociedade é esta, esta que ajudamos todos a fazer todos os dias através das nossas acções e omissões? (159)

Aquele desacordo com o próprio ser, essa Falta dele de que falam os versos de Alberto Pimenta são reconfigurados, em Meninos de ninguém, pela ênfase dada à complexidade da relação que se estabeleceu entre os jovens e Gisberta dias antes do crime, já que os primeiros meninos que a avistaram naquele edifício abandonado passaram a ajudá-la no início, inclusive levando-lhe comida, e mesmo um deles já a havia conhecido oito anos antes. Em que momento a mão estendida dá lugar a uma barbárie cometida em grupo? No texto que abre o livro, “Iá, um dia foi bater na Gisberta,” lemos:

Um grupo de rapazes rabiscava uma parede do prédio quando a viu entrar. Um deles correu para ela. Conhecera-a oito anos antes. Conhecera-a quando a mãe se prostituía na Rua Coelho Neto e a antiga estrela transexual se prostituía na Rua Gonçalo Cristóvão. Lembrava-se bem de Gisberta. Gisberta frequentava a casa da sua ama, ajudara a cuidar dele.

O rapaz passou a visitá-la no intervalo do almoço. Com ele vinham outros dois. Gi abriu-lhes a sua vida. E a sua vida era o cocktail de doenças, a miséria, a solidão (Pereira 15-16).

A partir de uma entrevista que fez a quem chama de “D.," a jornalista vai mostrando detalhes de como os miúdos foram se aproximando de Gisberta, contando toda a tragédia desde a perspectiva do menor e, ao mesmo tempo, dando a entender que a tragédia não começa ali, posto que há toda uma cadeia de 
Athayde

violência e maus-tratos a que o próprio "D." havia sido submetido desde a primeira infância. Imersos numa “cultura de gang,” suas histórias de vida são marcadas pelo abandono familiar e pelo abandono do poder público (que financiava a instituição católica sem, no entanto, se preocupar em garantir a preservação da saúde mental e física dos jovens institucionalizados).

O fato de Gisberta ser transexual, também assinala a reportagem, foi o que despertou a curiosidade de outros jovens da instituição de acolhimento que ficava nas proximidades do prédio abandonado, a Oficina de São José. Os meninos que haviam descoberto Gisberta chamaram outros para "ver um homem com mamas, que fizera operações à cara, usava cabelos compridos, pintava os lábios, os olhos e parecia mesmo uma mulher” (Pereira 151). Foi esse discurso transfóbico que, como descreve Ana Cristina Pereira, tornou-se o fator nevrálgico para despoletar a mudança de comportamento do grupo, que passou de três miúdos solícitos à “Gi," inicialmente, a 14 jovens que se envolveram, de uma forma ou de outra, no crime.

- Batiam-lhe e riam-se?

- Iá.

- O que havia nela que dava vontade de rir?

- Vestia-se de mulher.

Na quarta-feira, à hora do almoço, Gisberta estava dentro da tenda e D. gritou-lhe ao chegar: 'Não te disse já que não te queria aqui?' Ela saiu, suplicou-lhes que a deixassem em paz. Um rapaz atiroulhe uma pedra à cabeça, ela caiu. Quando se conseguiu levantar, D. passou-lhe uma rasteira e ela tornou a cair. Pontapearam-na, bateram-lhe com paus, baixaram-lhe as calças para ver se tinha pénis ou vagina (Pereira 17-18).

Meninos de ninguém, que inclui duas reportagens sobre o caso, sendo a segunda um tanto mais literária, se tornou uma das principais fontes documentais que viriam a ser utilizadas na criação de outras obras sobre o caso Gisberta, dentre as quais o romance Pão de açúcar (2018), que exigiu de Afonso Reis Cabral uma longa investigação e intenso trabalho de campo. Se no livro-reportagem, como vimos, Ana Cristina Pereira acompanha a vida de alguns dos menores, tornando Gisberta presente a partir do olhar deles, Afonso Reis Cabral leva essa 
perspectiva mais além, prolongando-a na ficção. Os dois autores enfatizam que, com os pontos de vista que adotam, não procuram desculpabilizar o crime, mas tornar mais humanos os envolvidos, alertando para a realidade de violência, miséria e sofrimento que a todos ali rodeia. "Eu tentei, pelo menos tentei, que todos estivessem humanizados, que todos tivessem uma vida própria, sem que isto queira dizer desculpar ou relativizar... não, é mostrar. Aliás, no livro não faço qualquer interpretação moral da história em relação a ninguém,” afirma Cabral (Silva e Matias). Para o escritor, em meio a tantas histórias violentas, esta surpreende pela forma como nos ensina sobre o desamparo, sobre a humanidade.

Esse romance-reportagem traz muitos elementos factuais dos últimos dias de Gisberta, desde quando os adolescentes a conhecem até o momento em que a assassinam — mas tudo contado por um narrador em primeira pessoa, que é um desses adolescentes, o Rafa. O narrador, portanto, está implicado na história e, mais uma vez, é um “olhar de fora” sobre Gisberta. Ademais, para resolver um problema de cariz, diríamos, neo-realista (como um adolescente com pouca escolaridade, inserido numa complicada realidade social, contaria uma história com profundas camadas de escrita e reflexão?), o autor, no prefácio intitulado “Nota antes,” faz um pacto com o Rafa personagem: “A história é tua, é como se fosses tu a contá-la, mas eu faço-o por ti” (Cabral 13). Assim, como ainda assinala, procurou com esse pacto legitimar o tom poético da narrativa e a complexidade interior das personagens, embora não tenha conseguido evitar, entretanto, que a verossimilhança fosse por vezes interrompida pela discrepância entre a realidade do protagonista e as reflexões que ele faz sobre a vida e o humano.

Em se tratando de um livro eficaz na elaboração representacional e na recriação factual, mais do que na criação de atmosferas, pelo menos no sentido gumbrechtiano, ainda que haja uma notável preocupação em envolver o leitor naqueles ambientes, é curioso observar que o edifício abandonado no centro do Porto se torna uma personagem, tanto quanto o próprio título sugere: Pão de Açúcar é o nome dado àquela construção embargada, que seria um centro comercial, e na qual Gisberta armou uma barraca onde passou a viver, com as poucas coisas que lhe restara. Ao ir buscar o nome à realidade e redimensioná-lo na ficção, Afonso Reis Cabral engenhosamente reaproveita-o como espaço semântico comum que liga Portugal ao Brasil naquela história—tal como a própria Gisberta. Como se sabe, a expressão pão de açúcar está associada a uma 
Athayde

das paisagens emblemáticas do Brasil, cartão-postal do país, de onde inclusive se pode ver o Cristo Redentor, de braços abertos, abençoando a cidade. Longe daquela ideia de lugar encantador que geralmente é associada ao termo, o pão de açúcar de Pão de Açúcar se torna uma personagem à medida que o lugar vai sendo personificado à propósito da própria tragédia que nele se insere, manifestando toda a aridez, abandono, degradação que há naquela história.

Já no romance Do fundo do poço se vê a lua (2010), o que se observa é que não existe compromisso algum com o factual—a história, aliás, se passa no Egito, a partir de uma tragédia que separa, na juventude, irmãos gêmeos brasileiros. Um deles acaba indo morar no Cairo, onde assume a sua identidade transexual e se torna uma dançarina em clubes noturnos. É essa protagonista Cleo, que carrega traços de Gisberta e sua história, que volta (machadianamente) da morte para narrar o romance. A questão do nome é, também aqui, fulcral na narrativa, surgindo sobremaneira articulada com o fato de se tratar de uma "defuntoprotagonista," que vê tudo de forma oniscientemente retrospectiva: "No fundo eu reunia esperanças de que aquele eu do passado pudesse compreender suas aflições futuras e, quem sabe, assinar ao final da mensagem seu verdadeiro nome, meu nome secreto" (Terron 259). Outro dos recursos estratégicos que Joca Reiners Terron utiliza para coadunar a criação narrativa com a identidade fragmentada da protagonista são as várias sequências do diário que Cleo começa a escrever em um hospital no Cairo, quando já havia feito a cirurgia de redesignação sexual e na altura em que perde a memória, em fragmentos que vão sendo intercalados ao longo da narrativa: “31 de janeiro de 1986 / Já faz tempo que não tenho nome algum. Ao menos é isto o que a plaquinha dependurada ao pé da minha cama aqui no hospital diz: 'Nome: desconhecido'” (Terron 106). Como se pode ver, também neste livro a questão do narrador contribui para pensarmos naquela Gisberta presente-ausente. Embora se trate de uma narrativa em primeira pessoa, desde o início a protagonista nos deixa saber: "Eu poderia chamar isto de uma espécie de autobiografia na terceira pessoa” (Terron 29), evidenciando assim a ficcionalização como mecanismo basilar da memória. Há aqui uma habilidosa estratégia narrativa, ao se assumir a perspectiva de que uma autobiografia é sempre a criação da história de um outro, pelo que Terron consegue fugir, desse modo, do terreno convencional da autoficção biográfica, num cenário literário marcado atualmente pela exacerbada valorização da primeira pessoa (ou num ecossistema global cada vez mais mobilizado pelo self). 
Essa variação do narrador em primeira pessoa que, por vezes, se torna um narrador em terceira pessoa acontece em vários momentos do romance, fazendo com que esse espaço que se move entre a linguagem autoficcional, com o seu aspecto referencial, e uma possível perspectiva autônoma do narrador seja tomado por relatos tão híbridos quanto a própria construção da identidade de Cleo. Tal como se observa, por exemplo, numa das mais duras passagens do livro, já no final, quando a protagonista está contando como foi monstruosamente agredida até a morte: "Estar morta é ver a sua própria vida oscilando entre a terceira e a primeira pessoa, como se a alma, na iminência de ir embora em definitivo e que a todos os fatos de uma existência observa, vê tudo simultaneamente do lado de dentro e do lado de fora” (Terron 278).

No romance, a questão da identidade se espraia nesse ver-se de fora para dentro e de dentro para fora, que Joca Reiners Terron tão bem articula, sobretudo da segunda parte em diante. Desde então, a história ganha um ritmo aprisionante, quando o autor se livra da necessidade de fazer um livro-wikipedia, mal de que sofre sua geração, em que parece que "tudo" tem que caber lá dentro (e ser explicado). A engenhosa tensão está toda nas oscilações e ambivalências entre ficção e realidade possibilitadas a partir da iminência desse fora/dentro, como numa trajetória diaspórica, em que se está fora mas preso por dentro, num estado de êxodo permanente. Tal como Gisberta, habitando um espaço luso-brasileiro, Cleo, vivendo num mundo disperso entre Brasil e Egito, também cumpre o seu destino diaspórico. Como nos mostra Virgínea Novack Santos da Rocha, esse ciclo de vida é reproduzido frequentemente nas narrativas que possuem transexuais como protagonistas: “(1) uma estrutura familiar que silencia e/ou exclui a criança, (2) uma necessidade de deslocamento geográfico e (3) a morte prematura da transexual” (5). Em suma, é como se o “peça a peça” de uma mulher transexual tentando construir a sua identidade fosse um aspecto transversal ao exercício da escrita, em que Cleo muitas vezes conta a sua história como se fosse a de outra pessoa, ou de outras pessoas, acolhendo na sua história a história de outras e, ao mesmo tempo, reproduzindo o ciclo.

Diante desse ciclo, se há um elemento que se repete tanto no romance quanto em várias outras daquelas obras é o vestido. Dando ênfase ao ato identitário de se vestir, de se travestir, de se transvestir, o vestido evoca um espaço alegórico no qual muitas vezes a imagem de Gisberta é associada ao processo de criar (de vestir) uma personagem. O espetáculo Gisberta, por exemplo, começa 
precisamente com a ideia da peça de roupa que se confunde com a peça teatral e o ato de vestir uma personagem, curiosamente numa encenação onde apenas um ator interpreta todos os personagens e usa sempre o mesmo figurino, movendose num cenário que não muda, de modo que o que se sobressai na diferenciação das personagens é tão somente a força do gesto de interpretação. Na primeira cena, ouvimos a irmã de Gisberta dizer:

No armário ficaram umas roupas. Poucas. A maioria ela levou. Ela não estava aqui, mas as roupas estavam. Tudo muito bonito, muito vistoso, sabe? A gente tinha que doar aquilo, fazer o quê, né, tinha que doar. Porque nenhuma pessoa morre completamente se a gente guarda as coisas dela. [...]

O armário ia esvaziando e esse vestido teimava em ficar lá dentro. Era azul. Todo de lantejoula. Tinha umas borboletas, um monte delas. Te pergunto: pra quem eu vou dar isso? Quem vai querer? Quem eu conheço em São Paulo que vai usar um vestido de lantejoula cheio de borboleta? É uma roupa de artista. Porque artista quando sobe no palco precisa brilhar. (Souza-Ribeiro 2)

Em Do fundo do poço se vê a lua, o vestido é o elemento que aparece ao longo de todo o diário disperso pelo livro, com passagens inseridas em diferentes partes da trama. O vestido é o elemento que liga Cleo ao seu passado, uma vez que a sua identidade transexual é assumida somente quando os seus pais morrem numa tragédia, da qual ela sobrevive (e o seu irmão gêmeo também), mas perde a memória, num processo que vai permiti-la renascer, tornar-se aquilo que se é. É ainda no início da história que o diário chega às mãos do irmão gêmeo William, que vai atrás do irmão no Cairo depois de receber um cartão-postal dele-e o que ali encontra é o caderno com anotações íntimas, contando da transformação de Wilson em Cleo. Na entrada do dia 10 de março de 1986, por exemplo, Cleo escreve: "Nelson desatou os barbantes, e então aconteceu a revelação e ele exibiu o vestido que eu usava na noite em que me encontraram inconsciente, quase um ano atrás. Eu usava um vestido” (Terron 114). Tal alusão ganha força em entradas seguintes, como na de 12 de março de 1986: "Dia a dia, esse vestido adquire dimensões fantasmagóricas pra mim. Dependurando no espaldar da cadeira, ao ser iluminado pela lua que entra pela janela, ele parece flutuar. As notícias que 
esse fantasma traz do passado não são nada alentadoras” (115). E já muito mais adiante, continuamos a observar a insistência de que "Não existe nada mais importante pra mim do que aquele pedaço de tecido [o vestido] meio gasto" (131), como diz numa das anotações meses mais tarde, noutra altura do livro, a 18 de novembro de 1986. É essa peça de roupa que faz a conexão de Cleo com o seu passado, do qual nada se lembrava.

Além do vestido, outro elemento que se repete em todas aquelas obras é o poço de água e a forma cruel como Gisberta morre, não tendo nenhum autor (ainda) ousado reescrever o desfecho dessa história, tal como brilhantemente fez Quentin Tarantino este ano com o seu Once Upon a Time... in Hollywood, criando um novo (e surpreendente) fim para o assassinato da atriz Sharon Tate, no final dos anos 1960. Mesmo a imaginação mais kitsch de um autor como Joca Reiners Terron nos leva aqui para um desfecho onde permanece a escuridão da noite, apenas iluminada pela lua, enquanto a violenta morte se aproxima:

Eu atendo aos pedidos de silêncio da Lua e das estrelas e peço a elas que também conversem baixinho para não me acordar.

Eu fecho meus olhos.

Eu calo minha boca. (279)

Estas são as últimas palavras de Cleo, que tem a sua "boca calada” ao ser jogada num poço, atravessando toda a noite na penúria agonizante da morte—cena de que dá conta o próprio título do livro. Lembremos que, no caso de Gisberta, ela ainda respirava quando os jovens a atiraram no poço profundo daquele edifício, achando que ela já estava morta e que, arremessando o seu corpo ali, ninguém o encontraria (não fosse um deles ter contado à professora, poucos dias depois, tudo o que havia se passado). Esse episódio foi evocado pelo tribunal para justificar a amenização da sentença, trazendo a público um caloroso debate sobre crimes de ódio, o que inclusive teve implicações na alteração da legislação portuguesa anos depois. ${ }^{3}$ Na peça Gisberta, uma das cenas a caminho do

${ }^{3}$ O homicídio de Gisberta contribuiu decisivamente para que fossem feitas modificações na legislação portuguesa. A revisão do Código Penal Português, em 2013, passou a incluir a "identidade de gênero" como categoria de discriminação nos artigos referentes a homicídios qualificados e ofensas à integridade física qualificadas, prevendo o agravamento penal se a motivação do crime tiver sido em função da identidade de gênero. Além disso, com a Lei n. ${ }^{\circ}$ 
desfecho traz a leitura da parte final da sentença, provocando impacto no público ao confrontá-lo com a reapropriação daquelas palavras: “[...] considerou, pois, este Tribunal que a brincadeira de mau gosto correu mal, mas a estes menores não se pode imputar a prática de um homicídio qualificado, e sim, e tão somente, a prática consumada de um crime de ofensas corporais e consequente omissão de socorro" (Souza-Ribeiro 14, itálico meu), lê-se no documento assinado a $1^{\circ}$ de agosto de 2006, atribuindo aos menores pena máxima de 13 meses.

No romance Pão de açúcar, desde o início o protagonista Rafa está a prenunciar o fim. Ao procurar edifícios abandonados no centro do Porto para grafitar, antes mesmo de conhecer Gisberta, assinala: "Eu imaginava-me no fundo de um poço. Um passo em falso e caía, contorcido na lama e na água estagnada" (Cabral 18). Esse "fundo do poço," ao mesmo tempo que denuncia a situação penosa na qual aquele menino se encontrava, acaba por literalmente representar o espaço a que toda aquela tragédia estaria confinada. Estavam todos, de uma forma ou de outra, num poço sem fundo. Tanto é que, ainda no começo do livro, no momento em que Rafa conhece Gisberta, vivendo então de forma precária numa tenda nas ruínas daquele prédio, é sintomática a sua primeira reação: "andava um cheiro a almíscar que me enojou. Como é que se vivia assim? Até eu, de quem tanta gente podia julgar o mesmo, como é que eu vivia assim, pensei que era impossível e absurdo alguém se isolar no fundo de uma cave, no fundo de uma barraca, no fundo da vida” (Cabral 46).

O poço está em tudo, inclusive na "altura da queda,” como também pressente Cleo, já a caminhar para o final da trama. Ao ouvir a palavra “altura,” pensa: "Fffffffffffffiffffffffffffffffiiiiiiiiiiiuuuuuuuuu. / Fiquei só medindo o tamanho da queda. / E então adormeci” (Terron 253). É o eco desse poço que do mesmo modo escutamos na canção de Pedro Abrunhosa, cujo fim anuncia: "E a distância até ao fundo é tão pequena, / No fundo, é tão pequena, / A queda” (Abrunhosa 2007). Além disso, em Indulgência plenária, entre a Casta diva de Bellini e um trecho de Othello cantado por Desdemona, dois dos seus versos finais associam Gisberta a uma árvore que só sobrevive “próxima da água” (definição de Salix em celta):

7/2011, de 15 de março, a ordem jurídica portuguesa autorizou a mudança de sexo e o registro de nome próprio em função da orientação sexual nas Conservatórias de Registro Civil. 


\author{
se assim for \\ nem o Diabo impedirá \\ que o teu aroma nostálgico \\ continue a manifestar \\ a deusa \\ em todas as suas faces \\ humanas
}

Gisberta Salce

Salgueiro Salix

chegou cá há muito tempo uma voz

que eu não percebo

mas também nunca

nunca me interessou perceber

perceber aonde se pode chegar (Pimenta 54)

A analogia a esta árvore, que é usada para combater superfícies dolorosas porque tem propriedades analgésicas, funciona, no desfecho, com o mesmo efeito catártico do próprio título do livro, que alude ao perdão das penalidades que eram dadas pela Igreja Católica aos fiéis diante de seus pecados (somente as indulgências plenárias outorgavam o perdão total, enquanto as demais indulgências previam apenas a remissão parcial da pena). Gisberta recebe, no fim, pela voz do poeta, a sua indulgência plenária, curando as feridas, ressurgindo como um Salgueiro Salix, cujas medidas não cabem naquele poço.

\title{
A narrativa-arquivo do ausente, quando já não há medida
}

Ao olhar atentamente para esse conjunto de obras, a conclusão a que chego é a de que Gisberta, mais do que uma personagem, pode ser compreendida como uma narrativa — uma narrativa transmidiática, transcultural, transtextual, que existe sempre na condição potencial de convocar uma série de aspectos significativos destes nossos tempos. Em um mundo de narrativas "destotalizadas, fragmentos de una visualidade sin historia” (Canclini 22), quando já nenhuma grande narrativa cria e organiza a imagem que a sociedade tem de si mesma, a 
Athayde

narrativa continuada de Gisberta reside na experimentação dos modos de representar ou aludir ao real, em modos de dizer que não chegam a se pronunciar completamente, superando a ideia de uma imagem-símbolo estanque e perpetuando uma condição sempre transitória da imagem. Trata-se de uma narrativa fundamentalmente polissêmica, que integra múltiplos contextos em diferentes mídias e que, existindo sempre na iminência do real, chama para si um território transgênero, em que tudo pode caber nele, onde as possibilidades são muitas, ou todas.

Claro está, Gisberta, presentificada pela emergência de vozes amplificadas nos últimos anos pelas mídias digitais, longe de ser a ausência do nome, vai se tornando o nome da ausência (aliás, prestem atenção como estou sempre a repetir o seu nome, sem nunca conseguir encontrar-lhe um metônimo preciso-neste ensaio, por exemplo, já mencionei 95 vezes o nome Gisberta). Essa sua ausência insistentemente permanente na construção de uma ampla narrativa, portanto, nos interpela a partir de uma "estética da iminência” (Canclini 12), inclusive porque o referencial da violência não é aqui puramente um contexto, mas a matéria bruta da qual as obras partem, é a própria presença desmaterializada de Gisberta, a ausência do testemunho que foi calado, as ruínas sobre as quais novas coisas foram erguidas. Gisberta e a sua história não são as ruínas, mas as novas coisas que foram erguidas. "O que resta” mostra o que não aparece, o que não foi dito, o que a obra está permanentemente a insinuar.

Neste sentido, diferentemente do caso de uma Frida Kahlo, que eu também venho estudando—no qual a digitalização e difusão do seu arquivo, que ficou fechado durante 50 anos, levou à criação do que chamo de um autor-arquivo-, aqui estamos lidando com uma narrativa-arquivo, que parte justamente daquela ausência (inclusive material) que Gisberta deixou, enquanto personagem que existe porque (já) não existe. Explico melhor. Em tempos que nos levam a aprender a manejar aspectos de nossa identidade através da potencialidade das interfaces digitais, a força da imagem de Gisberta reside na capacidade de sua história criar uma espécie de contracultura do arquivamento, que “dibuja por lo tanto un escenario en el cual el coleccionismo de archivos aparece como el nuevo terreno de batalla para agenciarse el poder de enunciar otros relatos antes silenciados o el poder de dejar expresarse a otros sujetos políticos” (Barriendos 128). 
Se no século XX houve uma expansão massiva daqueles que podiam ter a sua imagem publicada e passível de ser arquivada, aumentando-se extensivamente a quantidade e a difusão de imagens, neste século as consequências são bem mais complexas. Como se observa, estamos lidando com uma quantidade de dados nunca antes vista, já que as novas mídias vieram possibilitar uma avalanche de produção documental sem precedentes na história (Beiguelman 28). Nunca produzimos, editamos, armazenamos e difundimos tantos arquivos como agora, num processo exponenciado pelo desenvolvimento das tecnologias digitais (basta pensar na quantidade de informações e imagens que temos guardadas no celular e no computador, bem como no tempo que gastamos diariamente manipulando arquivos nesses dispositivos). De modo que, se no século anterior passamos a considerar que "a estrutura técnica do arquivamento determina o próprio conteúdo do arquivo, tanto em sua atualidade como em sua relação com o futuro" (Kujawski 80), agora, com o digital, cada vez mais será tão somente a estrutura do arquivamento o que passa a existir: já não se trata de uma narrativa-do-arquivo, mas de uma narrativa-arquivo de que falamos, e por isso tem se tornado tão urgente realizar discussões sobre a estética do banco de dados e a emergência da curadoria da informação.

Em suma, no mundo em que a imagem tem vindo a ocupar o lugar da escrita no sistema privilegiado da troca de informações, a imagem de Gisberta circula não como resultado da eficácia documental do arquivo que ela deixou (ela quase nada deixou e a escassa documentação que se tem dela foi guardada por familiares e amigos), mas a partir da documentação dispersa que foi sendo gerada sobre a sua história. Como se pode imaginar, há uma obsessão documental que atravessa grande parte daquelas obras, à procura de qualquer material que tenha sobrevivido às ruínas ou que tenha sido delas testemunha, da referência aos poucos objetos achados com Gisberta à informação meteorológica sobre o dia de sua morte. Em Pão de açúcar, por exemplo, num dos primeiros capítulos, deparamo-nos com uma lista detalhada dos pertences que foram encontrados na barraca dela (Cabral 46), elencados a partir da descrição feita no processo judicial. A enunciação daqueles itens também ocorre em Meninos de ninguém (Pereira 19), numa passagem adaptada pelo documentário A Gis, cujo início é marcado pela enumeração de cada um dos objetos.

Além desta cena inicial, um dos momentos de grande impacto do filme é quando exibe cartões-postais que Gisberta enviou para a família em suas viagens 
Athayde

pela Europa. A digitalização e exibição desses postais recuperam, em certa medida, o testemunho histórico, no sentido benjaminiano, as marcas que testemunham a passagem do tempo, as amarras histórico-espaciais que nos tornam qualquer coisa mais próximos do passado. Das características da letra aos erros de grafia e a dificuldade em escrever, do tipo de papel à qualidade da impressão, e todas as manchas do tempo. Também há os beijos registrados com batom rosa, denunciando no postal as transformações pelas quais havia passado "Gisbert," como então passou a assinar, sem o indicativo de gênero. E o mais importante de tudo: a única vez que escutamos Gisberta falar é nesses postais, as únicas frases que partiram dela, escritas ali, no avesso daquelas fotografias dos anos 1980, mostrando lugares que povoavam o imaginário brasileiro, e tão distantes dele, e tão distantes da família que os recebia. É muito interessante observar, nesse mundo digital onde triunfou a circulação oblíqua dos objetos, essa aura da inscrição tempo-espacial que os cartões-postais evocam, somada ao espaço performático da digitalização feita por um familiar e à visualização encenada pelo documentário, alcançando um efeito surpreendente.

A imagem de Gisberta é potenciada, portanto, por essa sobrevida do analógico em meio digital, considerando-se que nele o contexto muitas vezes se torna o conteúdo, como sugere Margot Lovejoy (2004). Com efeito, as novas mídias ampliam o nosso presente preenchendo-o com narrativas do passado, fazendo com que o passado se torne presente (e um novo presente) através de um tempo inaugural, "o do presente que não foi,” como afirma Giselle Beiguelman (28). Quer dizer, procura-se monumentalizar o presente ao transformá-lo numa re-produção encenada do passado, então emulado por produções midiáticas que fazem regressar um tsunami de imagens do que já não existe. É Gisberta também fruto desse tempo, desse presente que não foi, em um caso que mostra que, se por um lado essas novas formas de consumo levam a um esvaziamento da narrativa histórica, ao mesmo tempo há uma potência disruptiva nisto tudo. Existe um território possivelmente subversivo nesse mundo onde tudo vai sendo engolido pela programming language e se tornando uma sofisticada arquitetura de banco de dados. As novas tecnologias de registro e a consequente expansão dos processos de digitalização favorecem o contato substancial com novas formas de tocarmos o passado e de lidarmos com os nossos mortos, de reativarmos os seus mundos não como uma fonte de entretenimento, mas a partir 
de uma apropriação política da imagem que as novas tecnologias de arquivação permitem. É aqui onde ressurge Gisberta.
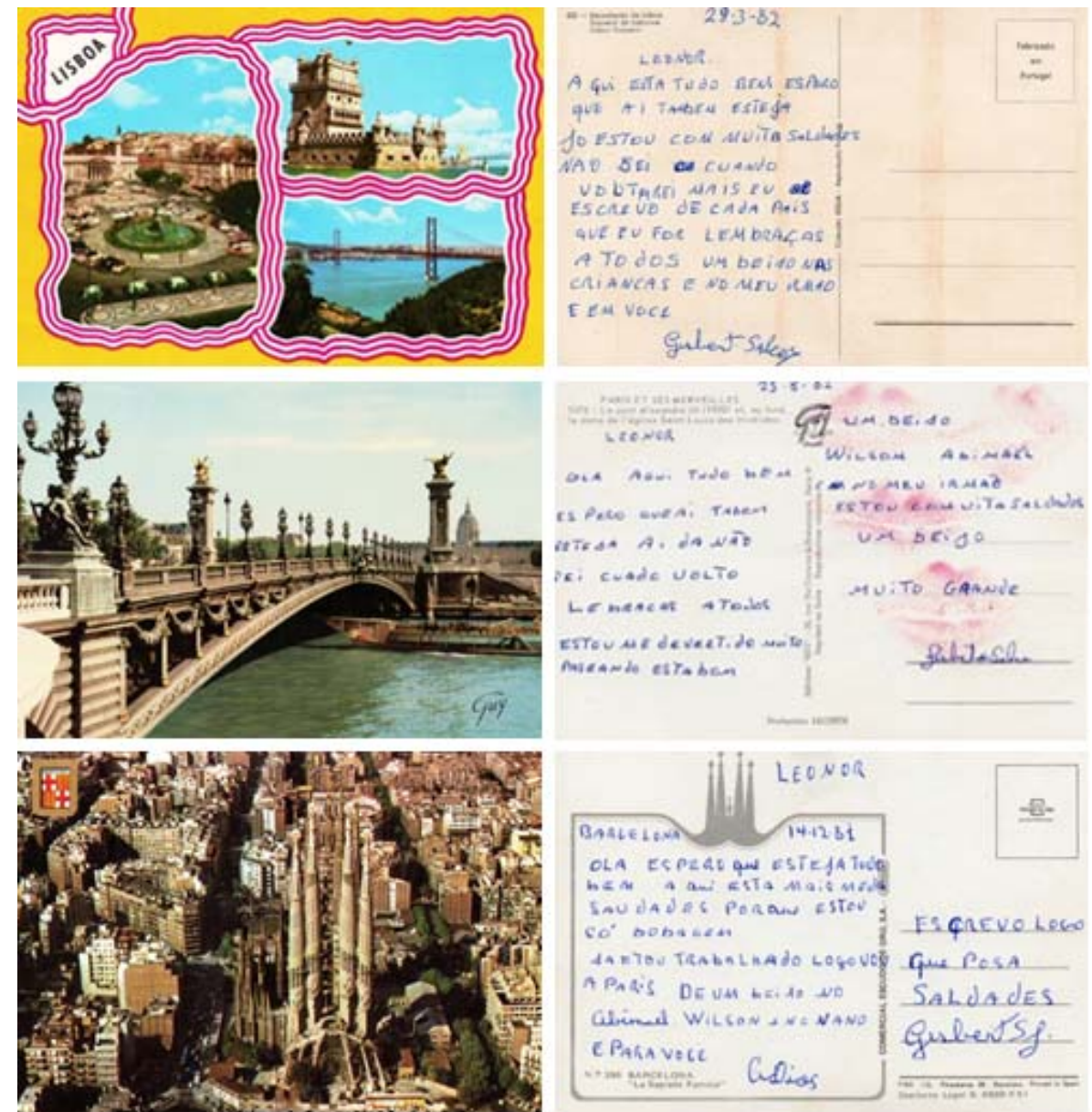

Fig. 2. Frames de cartões-postais reproduzidos pelo documentário A Gis.

Gisberta envia os postais para a sua família, no Brasil, na altura em que vai morar em Portugal e visita outros países na Europa.

As estratégias criativas dessas novas formas de arquivamento têm a ver com "una subversión crucial que el arte sostiene en el espacio del archivo de las imágenes,” como afirma Andrés Maximiliano Tello (133). O que significa dizer que "la subversión del archivo implica su destrucción como espacio de 
Athayde

administración privilegiado del tiempo histórico, de las cronologías y biografías, de las clasificaciones sociales y culturales, incitando de esa forma la reflexión crítica de los espectadores” (140). Afinal, o arquivo foi concebido, na tradição ocidental, como uma unidade que dava conta de como, de fato, os fatos ocorreram e se sucederam na história, como o instrumento de uma história que teria sido em si mesma. Desde pelo menos uma perspectiva foucaultiana e depois derridiana, no entanto, o arquivo deixa de ser essencialmente assim visto e passa a ser pensado na sua condição de espectralidade (Derrida 2001), sendo encarado como uma das muitas narrativas possíveis que podem ser projetadas a partir de uma mesma base documental. Daí a possibilidade infinita de se conjugar seus elementos, ligando o ato arquivante fundamentalmente a uma perspectiva de presente-futuro, com a insistente abertura para o virtual ou vir a ser. A noção de arquivo pode mesmo ser entendida agora como uma espécie de tábula rasa das mídias, cuja memória está continuamente em reinvenção. Por isso, funciona como esse espaço em que as narrativas são subvertidas, inventadas, refeitas, recontextualizadas, pois não se trata mais de concebê-lo como um depósito que guarda o que de importante existe do passado, homogeneizando a complexidade documental, mas de entendê-lo como um discurso fundado em rasuras e lacunas, e que problematiza o esquecimento, o silêncio, o silenciamento.

Assim, ao se trabalhar com um arquivo queer neste contexto, como se propõe aqui, problematiza-se a essencialidade conceitual do arquivo procurando entendê-lo como, mais do que fonte de informação, um poderoso alicerce para a teorização das experiências e condições de existência de grupos silenciados. O caso de Gisberta avigora a noção de que um arquivo queer é tanto o resultado dos esforços para reunir, agenciar e difundir documentos de vidas queer, quanto consequência direta das reconfigurações teóricas do arquivo (Martínez 2014). Ao tornar ainda mais complexa a discussão sobre as dimensões retóricas do arquivamento, este tipo de arquivo fortalece a ideia de que, ao invés de se privilegiar uma hermenêutica da recuperação, presumindo-se que há uma verdade perdida ou silenciada que deve ser finalmente revelada, como nos diz Anjali Arondekar (2009), a procura deve ser pelos traços recursivos da documentação, mobilizando-os na criação de dispositivos narrativos que possam oferecer modos alternativos de conhecimento. Daí a importância da imaginação convocada, reconhecida e valorizada como fonte e recurso do arquivo, como sugere María Elena Martínez (2014). É dessa profícua imaginação que resulta a 
"narrativa Gisberta," com aquele absolutamente diversificado conjunto de obras que cria um novo contexto para a imagem dela.

Além disso, se o arquivo sobrevive das tensões entre a produção de informação e a criação de narrativas, essas tensões se tornam ainda mais pronunciadas em casos como o de Gisberta. Tal como o seu arquivo, muitos outros possuem uma documentação escassa ou mesmo inexistente, manifestando na precariedade documental os dramas da existência queer. É o que se pode chamar de "missing archive" (Marshall, Murphy e Totorici), que mostra que a ausência ou carência de arquivo também gera arquivo, podendo-se encontrar uma série de estudos dedicados a arquivos que nunca existiram, como é inclusive o nosso caso. Claro está, entender o arquivo enquanto ausência implica consentir que as evidências materiais não são mais importantes do que o espaço dinâmico de interpretação dos documentos, repleto de intermitências e marcado pelas distensões entre ausência e presença na produção de conhecimento. Por esta razão, os investimentos na teorização do arquivo passam a ser tão significativos para se criar novas bases culturais quanto os esforços para a recolha, manutenção e preservação de documentos queer e a constituição de arquivos institucionais a eles dedicados. O que isto evidencia, afinal, é que não há prática de arquivamento que não seja marcada por formas de se pensar o arquivo.

Desse modo, podemos dizer que Gisberta fala através das possibilidades e limites do arquivo, que se manifestam especialmente por meio do exercício de escuta transversal a toda a sua narrativa. A sua memória é a memória do arquivo. Um caso como este nos mostra que o arquivo já não está somente na base ideológica da representação, mas também é um dos mais importantes alicerces da experiência estética dos nossos tempos, mediando os seus modos narrativos. Tal como Gisberta existe na sua condição de ausente, também o arquivo está na iminência do desaparecimento, por existirem sempre novas leituras sobre as leituras, porque cada gesto de inscrição do arquivo apaga uma leitura anterior, justificando a urgência da temporalidade em que se vive. Em síntese, Gisberta é essa urgente subversão narrativa que se refaz constantemente, dispersa, inacabada, revigorada, viva. Neste fim de década barulhento, tomado por romances e filmes que ensaiam mundos pós-apocalípticos onde já não se pode ver a luz do dia ou fazer qualquer som, nestes tempos em que o nosso medo está canalizado na pane súbita das conexões em rede, a narrativa de Gisberta surge, 
insistindo para que re-interpretemos as ausências silenciosas (e silenciadas) do arquivo. Mais do que nunca, em meio a tanto ruído, é necessário escutar.

\section{Obras citadas}

Alves Jr., Dirceu. "Renato Andrade recria a balada de Gisberta e aponta cinco outros personagens reais para o futuro.” Veja-São Paulo, 26 fev. 2017, vejasp.abril.com.br/blog/dirceu-alves-jr/renato-andrade-recria-a-balada-degisberta-e-aponta-cinco-outros-personagens-reais-para-o-futuro/.

Abrunhosa, Pedro. “Balada de Gisberta.” Luz, Universal Music Portugal, 2007.

“Atribuição do Prémio Arco-Íris 2014 à peça ‘Gisberta,' da autoria de Eduardo Gaspar e interpretada por Rita Ribeiro.” Associação ILGA Portugal, YouTube, 12 jan. 2015, www.youtube.com/watch?v=HQvCecfWzIU.

Arondekar, Anjali. For the Record: On Sexuality and the Colonial Archive in India. Duke UP, 2009.

Barriendos, Joaquín. "Reterritorializando los sesentas: Archivos, documentos y posestructuralismo en el museo de arte.” Arte, archivo y tecnología, edição de Alejandra Castillo e Cristián Gómez-Moya, U Finis Terrae, 2012, pp. 12543.

Beiguelman, Giselle. "Reinventar a memória é preciso.” Futuros possíveis: arte, museus e arquivos digitais, edição de Giselle Beiguelman e Ana Gonçalves Magalhães, U de São Paulo, 2014, pp. 12-33.

Beltrão, Maria. “Entrevista a Luis Lobianco.” Estúdio I: Globo News, 31 mar. 2017, vimeo.com/226216054.

Bethânia, Maria. "Balada de Gisberta.” Amor festa devoção, Biscoito Fino, 2010.

Cabral, Afonso Reis. Pão de açúcar. Dom Quixote, 2018.

Canclini, Néstor García. La sociedad sin relato: antropología y estética de la inminencia. Katz, 2010.

Carvalhaes, Thiago, director. A Gis. Divisão, 2016.

Costa, Darcielle, e Bernardo Gonçalves. “Gisberta eternizada no palco do Sá da Bandeira.” Jornalismo Porto Net, 29 nov. 2018, jpn.up.pt/2018/11/29/ gisberta-eternizada-no-palco-do-sa-da-bandeira/.

Derrida, Jacques. Mal de arquivo: uma impressão freudiana. Tradução de Claudia de Moraes Rego, Relume Dumará, 2001. 
"Entrevista com o diretor de A GIS, Thiago Carvalhaes." $28^{\circ}$ Festival Internacional de Curtas-Metragens de São Paulo, Curta Kinoforum, 20 set. 2017, youtube.com/ watch?v=WtFXd6679HA.

Fernandes, Luís. "Posfácio.” Meninos de ninguém: o caso Gisberta e outras histórias, de Ana Cristina Pereira, Ulisseia, 2009.

"Foi a primeira vez que a família foi procurada para falar sobre a Gisberta." Dezanove, 7 dez. 2018, dezanove.pt/foi-a-primeira-vez-que-a-familia-foi1221676.

Gumbrecht, Hans Ulrich. Atmosphere, Mood, Stimmung: On a Hidden Potential of Literature. Tradução de Erik Butler, Stanford UP, 2012.

Horta, Bruno. “'Gisberta' de choro e riso: peça de Luis Lobianco recorda transexual assassinada no Porto.” Observador, 24 nov. 2018, observador.pt/2018/11/24/gisberta-de-choro-e-riso-peca-de-luis-lobiancorecorda-transexual-assassinada-no-porto/.

Kujawski, Guilherme. “Arquivos: uma memória tripartida.” Futuros possíveis: arte, museus e arquivos digitais, edição de Giselle Beiguelman e Ana Gonçalves Magalhães, U de São Paulo, 2014, pp. 79-85.

Lovejoy, Margot. Digital Currents: Art in the Electronic Age. $3^{\text {a }}$ ed., Routledge, 2004.

Marshall, Daniel, Kevin P. Murphy e Zeb Tortorici. "Queering Archives, Historical Unravelings.” Radical History Review, no. 120, 2014, pp. 1-12.

Martínez, María Elena. “Archives, Bodies, and Imagination: The Case of Juana Aguilar and Queer Approaches to History, Sexuality, and Politics.” Radical History Review, no. 120, 2014, pp. 159-82.

Pereira, Ana Cristina. Meninos de ninguém: o caso Gisberta e outras histórias. Ulisseia, 2009.

Pimenta, Alberto. Indulgência plenária. \& etc., 2007.

Rocha, Virgínea Novack Santos da. Uma história que narro, uma experiência que não conheço: A representação de personagens trans* na literatura brasileira contemporânea. 2018. Pontifícia U Católica do Rio Grande do Sul, Dissertação de mestrado. Tede, tede2.pucrs.br/tede2/handle/tede/8310.

Silva, Sofia Matos, e Pedro Matias. “Afonso Reis Cabral: 'Pão de açúcar é uma conquista como escritor.”’ Jornalismo Porto Net, 11 out. 2018, jpn.up.pt/2018/10/11/afonso-reis-cabral-pao-de-acucar-e-uma-conquistacomo-escritor/. 
Souza-Ribeiro, Rafael, dramaturgo. Gisberta. Produção de Luis Lobianco, direção de Claudia Marques, 2017.

Tello, Andrés Maximiliano. "El arte y la subversión del archivo.” Aisthesis, no. 58, 2015, pp. 125-43.

Terron, Joca Reiners. Do fundo do poço se vê a lua. Companhia das Letras, 2010. 